\title{
Spatially Explicit Modelling of Extreme Weather and Climate Events Hot Spots for Cumulative Climate Change in Uganda
}

\author{
Ivan Bamweyana ${ }^{1}$, Lydia Mazzi Kayondo² \\ ${ }^{1}$ Part time Lecturer Dept. of Geomatics and Land Management, Makerere University P.O Box \\ 7062, Kampala, Uganda, email: IVANSON5@GMAIL.COM, Tel: +256782180350 \\ ${ }^{2}$ Lecturer Dept. of Geomatics and Land Management, Makerere University P.O Box 7062, \\ Kampala, Uganda, email: MKLYDIA@CEDAT.MAK.AC.UG, Tel: +256772491789
}

DOI: http://dx.doi.org/10.4314/sajg.v7i1.7

\begin{abstract}
The reality of climate change continues to influence the intensity and frequency of extreme weather events such as heat waves, droughts, floods, and landslides. The impacts of the cumulative interplay of these extreme weather and climate events variation continue to perturb governments causing a scramble into formation of mitigation policies. However, national scale composites of climate hotspots remain a bottle neck to this policy formation. This paper therefore, modelled the spatially explicit extreme weather and climate events indicators into a Uganda-national extreme weather and climate events composite hotspot indicator model. The hotspot model was mapped into decomposable sub-indicators based on the Geon concept. A spatial indicator framework was developed through literature review and expert knowledge. The resulting indicators were weighted using Principal Component Analysis (PCA) /factor analysis and then normalized. They were aggregated using Multi Criteria Decision Analysis (MCDA) tools in an Object Based Image Analysis (OBIA) environment. Sensitivity analysis was carried out to ascertain the influence and significance of the indicators in the resultant model. A cumulative climate change index model was hence analysed and mapped. The mapping provides spatially explicit information regarding climate extremes at national scale, consequently addressing its growing demand among public and private institutions. Further research, into the complex interactions of cumulative climatic factors and external components like ecological systems and anthropogenic biomes will go a long way in boosting climate information. This coupled with easy access to open web availability; if adopted, will readily inform national climate change policy at national level and greatly improve decision making within development sectors, hence mitigating the advance effects of climate change.
\end{abstract}

\section{Background}

Climate change is a global reality, and Uganda is no exception. Although developed nations contribute higher levels of greenhouse gases (GHG), developing nations like Uganda that have had miniscule contribution to global warming are feeling the impacts of climate change first and worst (Oxfam, 2008). According to Hepworth (2010), if the GHG emissions are not reduced, climate models consistently show an increase in global temperatures of up to $+4.30 \mathrm{C}$, and $+3.20 \mathrm{C}$ in East Africa by 2080. Similar consistence is observed in the models projecting a $7 \%$ increase in wetter conditions in the same period. These variations are likely to mean; increased food insecurity, soil 
erosion and land degradation, flood damage to infrastructure and settlements, shift in spread of diseases like malaria and shifts in agricultural productivity and natural resources. Such consequences of climate change inherently make Uganda highly vulnerable to the impacts of climate change (ACCRA, 2010).

Lavell et al., (2012) propose that, extreme weather and climate comprise the main facet of climate variability under stable or changing climate. They further define extreme events to mean the occurrence of value of a weather or climate variable above or below a threshold value of the range of observed values of the variable. Similarly, the IPCC, (2012) summary to policy makers argues that managing the risks of extreme events and disasters to advance climate change adaptation is best approached by assessing the scientific literature on issues that range from the relationship between climate change, extreme weather and climate events to their implications for society and sustainable development. Therefore, as much as the character and severity of impacts from climate extremes depend not only on extremes but also on exposure and vulnerability, this study explored and focused on the weather and extreme climate events that provide assessment concerns to a policy maker as a result of the interaction of climatic extremes with environmental and human factors triggering impacts and disasters.

Of recent, Climate change has forced itself on the agenda among Ugandan government ministries and agencies and is perceived as a 'hot topic' consequent to weather extremities of the 2007 floods, landslides, high temperature spells and repeated drought (Hepworth and Goulden 2008). Inevitably, government bodies and forums have scrambled into developing climate change related adaptation and mitigation policies. This is intended to shift the disaster management paradigm from the traditional emergency response focus to one of prevention and preparedness (Kaggwa et al., 2009). The climate assessments that associate national policy development deal with several spatial climate related indicators. However, these are often availed at global scale rather than national scale; and at single indicator and not composite indicator interaction level. The rarely resultant hotspot composites are also not often decomposable to sub-indicators and open accessibility to them remains a challenge. This creates a problem of non-precise national climatic composite assessments. Availing a framework for a regionalized decomposable and national climate hotspot index, will thus go a long way in easing access to climate index information and informing policies for effective climate change adaptation and mitigation among vulnerable communities across the country. This paper therefore, uses geospatial technologies to develop a spatially explicit tool anchored on climate change hotspot objectbased regionalization models for Uganda whilst utilizing the geon concept (Lang et al., 2010). This approach adopted by related research (Hagenlocher et al., 2013 and Kienbeger \&Hagenlocher 2014) provides not only an iterative but a continuously evolving process of climate resilient pathways to manage change within these complex systems. This in turn avails decomposable deliverables that make sustainable development the ultimate goal in national policy formation and considers mitigation as a way to keep climate change moderate rather than extreme. 


\section{Study Area}

Climate change in Uganda has started manifesting itself through increased frequency of extreme weather events, i.e. droughts, floods and landslides, pausing a serious threat to the country`s natural resources, social and economic development (NAPA, 2007). This research was therefore carried out within the spatial domain of the Republic of Uganda represented in Figure 1 for spatial delineation of extreme weather and climate change hotspots.

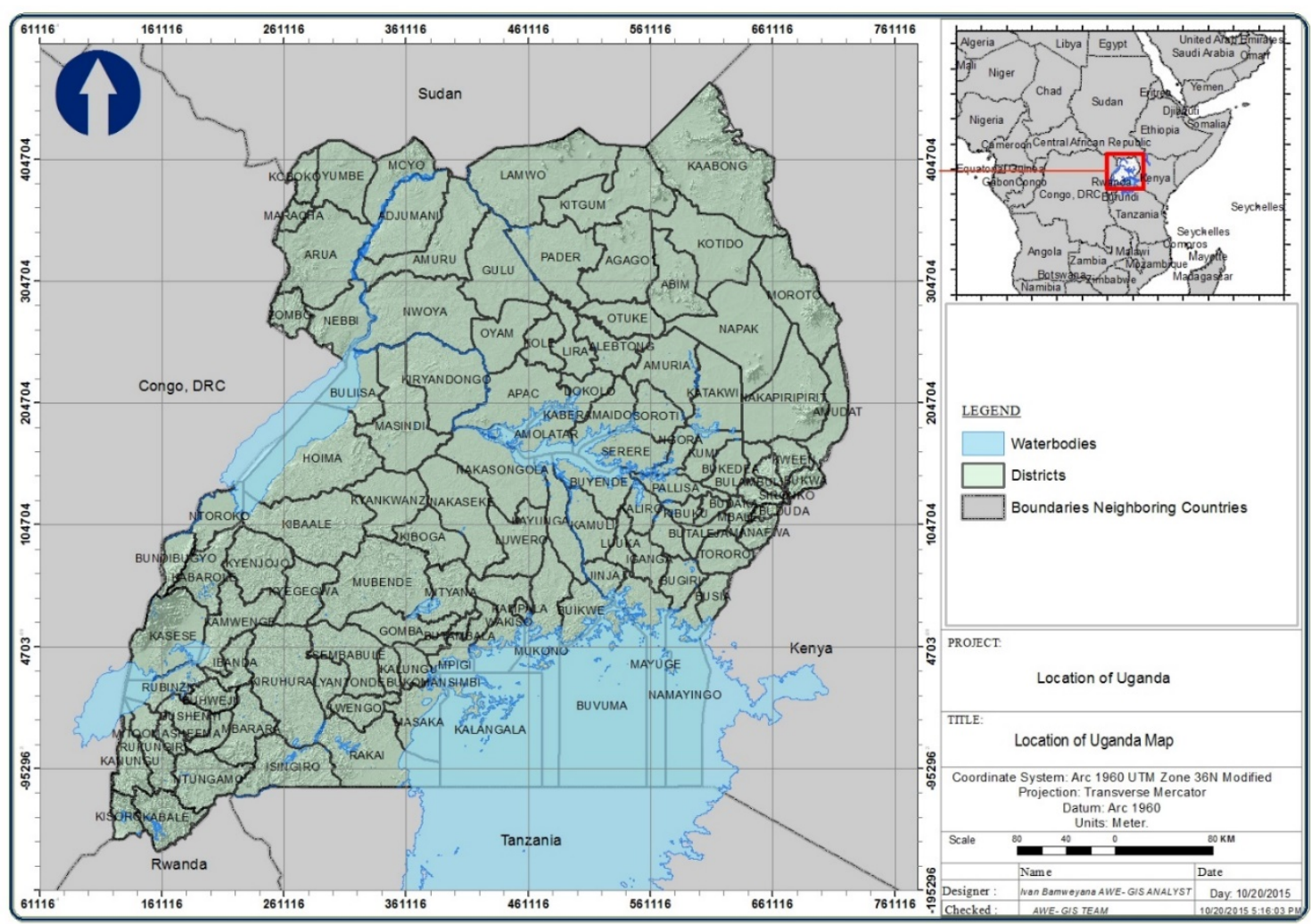

Figure: 1 Location map of Uganda

\section{Methodology}

Spatially explicit climate hotspots are direct derivatives of the integration of proxy multidimensional phenomena. The combination of the different dimensions of phenomena is achieved by applying the spatial composite index formation methodologies (Salzman et al., 2003; Mazziotta and Pareto, 2012). The construction of a composite index is a complex methodological flow based on phases, with each phase involving several alternatives and possibilities that have an effect on the quality and reliability of the results (Mazziotta and Pareto, 2013). Upon development of a theoretical framework and selection of variable, Trogu, (2014) spatialized the Organisation for Economic Co-operation and Development (OECD), (2011) general composite index construction as implied in Table 1 . This study adopted the spatial methodology workflow to cope with the geospatial nature of the datasets. 
Table: 1 Spatial Index construction workflow

\begin{tabular}{lc}
\hline \multicolumn{1}{c}{$\begin{array}{c}\text { OECD/JRC } \\
\text { Methodology }\end{array}$} & Spatial Methodology \\
\hline \multicolumn{1}{c}{ Definition and analysis of spatial indicator framework } \\
\hline $\begin{array}{l}\text { Data analysis } \\
\text { Multivariate analysis } \\
\text { Data normalization }\end{array}$ & $\begin{array}{c}\text { Definition of the theoretical framework } \\
\text { processing } \\
\text { Data normalization }\end{array}$ \\
\hline & $\begin{array}{c}\text { Weighting and } \\
\text { aggregation } \\
\text { Sensitivity analysis } \\
\text { Data Visualization }\end{array}$ \\
\hline
\end{tabular}

\subsection{Spatial Indicator framework}

Indicators that relate to extreme climate and weather events, were conceptualized through expert opinion and validated against literature review. Upon conceptualization, identified indicators were obtained from data custodian organizations that include; Uganda meteorological services, climatology analysis software like GeoClim of USGS/ FEWSNET (Famine early warning systems network), and DFO (Dartmouth flood inventory). Ideally, the indicators were adopted relative to their relevance, temporal scale, spatial scale, accessibility and soundness. Consequently, an indicator framework for extreme climate and weather events was developed (Table 2). The indicators with their respective proxies were evaluated and detailed in the same table. The framework is inclusive of indicators that had sufficient data over the cumulative time series subject to validation. The indicators also give the best spatial representation across the study area.

Table: 2 Extreme weather and climate events indicators and sources

\begin{tabular}{|c|c|c|c|}
\hline Dataset & Proxy & Available time series & Source \\
\hline Temperature & Temperature & $1981-2015$ & UMA,USGS/FEWSNET-GeoCLIM \\
\hline \multirow[t]{2}{*}{ Precipitation } & Average rainfall & $1981-2014$ & UMA,USGS/FEWSNET-GeoCLIM \\
\hline & Co-efficient of variation of rainfall & $1981-2014$ & UMA,USGS/FEWSNET-GeoCLIM \\
\hline Drought & Standardized Precipitation Index(SPI) & 1992,1997, 2002 & USGS/FEWSNET -GeoCLIM \\
\hline Flood events & Flood frequency & $1961-2015$ & UNEP/DFO \\
\hline
\end{tabular}




\subsection{Data Modelling and Indicator Processing}

\subsubsection{Data processing}

Precipitation related data was generated with aid from the GeoClim Climatology analysis tool. GeoClim is a tool that facilitates climatological analysis of rainfall and temperature data developed by United States Agency for International Development (USAID), United States Geological Survey (USGS) / (FEWS NET). GeoClim runs with climate Hazards Group Infra-Red Precipitation with (Station) (CHIRPS) data. The station data is added after calibration using in-situ / station data. The tool builds on approaches of 'smart' interpolation techniques, high resolution, and long period of record precipitation estimates based on infrared Cold Cloud Duration (CCD) observations.

The CHIRPS GeoClim tool comes with BASIICS (Background-Assisted Station Interpolation for Improved Climate Surfaces) component algorithm. The algorithm was used to blend the gridded datasets (CHIRP satellite data) with the station data obtained from the Uganda Meteorological Authority (UMA). The blending is done using a modified inverse distance weighting (IDW) approach that borrows from the concepts of kriging. The algorithm extracts values from the grid at all locations where the ground station data has valid values. The program then carries out least squares regression between the collocated point and the extracted grid values. It then out puts the R-squared $\left(\mathrm{R}^{2}\right)$ value in a statistical diagnostic file. The resultant satisfactory calibration product (CHIRPS) was then interrogated and rainfall, co-efficient of variation of rainfall, temperature and drought (SPI) proxy data generated. The already pre-processed flood data is generated by DFO. It is derived from news, government, institutional, and various remote sensing sources like Landsat and MODIS.

\subsubsection{Indicator Pre-Processing}

In order to facilitate further analysis, images must have similar properties such as; spatial extent, coordinate system and pixel size. To achieve this, the data obtained was subjected to conversion, resampling and aggregation, interpolating and transforming surface processes as shown in Figure 2.

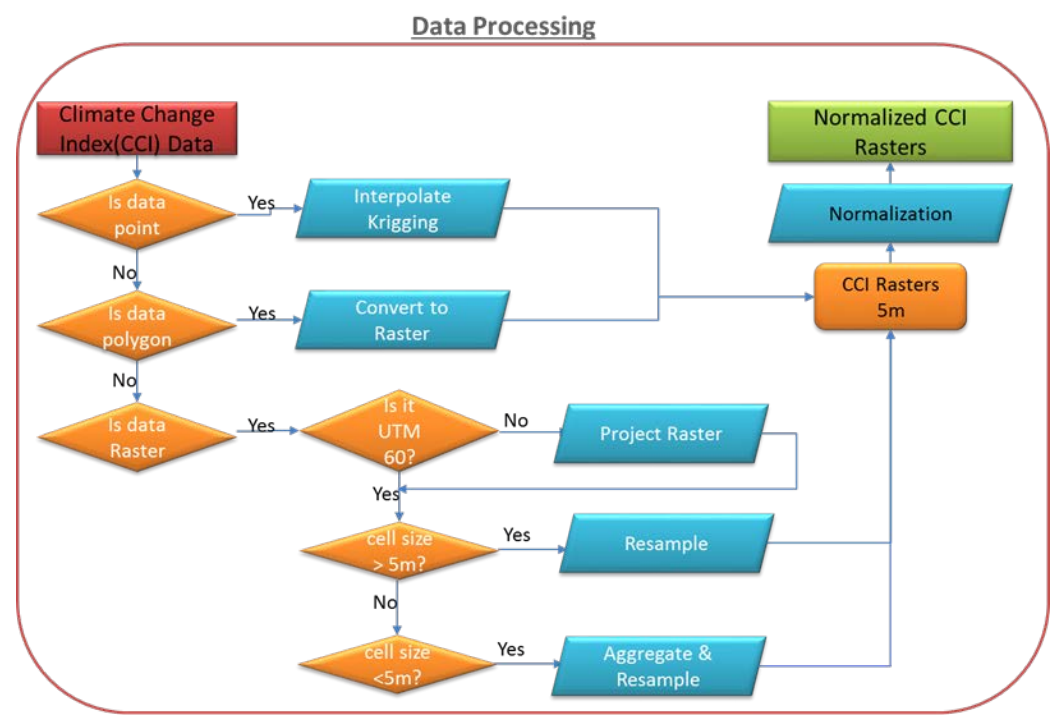

Figure:2 Indicator processing methodology flow chat 


\subsection{Surface Data Normalisation}

The identified indicators required normalization to render them comparable. Several normalization techniques exist for example, ranking, min-max transformation, and standardization (Freudenburg, 2003; Jacobs et al., 2004). However this study adopted the min-max method. This is because the minmax method has the ability to widen the range of indicators lying within a small interval (OECD, 2011) and further preserve relationships with in the data.

OECD (2011) handbook on constructing composite indicators details the min-max normalization as; - Each indicator $x_{q c}^{t}$ for a generic country c and time $t$ is transformed in;

$$
I_{q c}^{t}=\frac{x_{q c}^{t}-\min _{c}\left(x_{q}^{t}\right)}{\max _{c}\left(x_{q}^{t}\right)-\min _{c}\left(x_{q}^{t}\right)} \ldots \ldots \ldots \ldots \ldots \ldots \ldots \ldots 1
$$

Where $\min _{c}\left(x_{q}^{t}\right)$ and $\max _{c}\left(x_{q}^{t}\right)$ are the minimum and maximum value of $x_{q c}^{t}$ across all countries $c$ at time $t$. In this way, the normalized indicators $I_{q c}$ have values lying between 0 (laggard, $x_{q c}^{t}=$ $\min _{c}\left(x_{q}^{t}\right)$ ) and 1 (leader, $x_{q c}^{t}=\max _{c}\left(x_{q}^{t}\right)$ ).

\subsection{Indicator Mapping}

The application of the above techniques resulted into the mapping of temperature (A), Rainfall (B), Flood (C), drought (D) Co-efficient of variation of rainfall (E) as individual indicators represented in Figure 3. The scale is on a continuum of red to green, with red representing the area's most susceptible to extremities of the corresponding weather and climate indicator. The green represents the area's least susceptible to natural extremities of the corresponding weather and climate indicator.

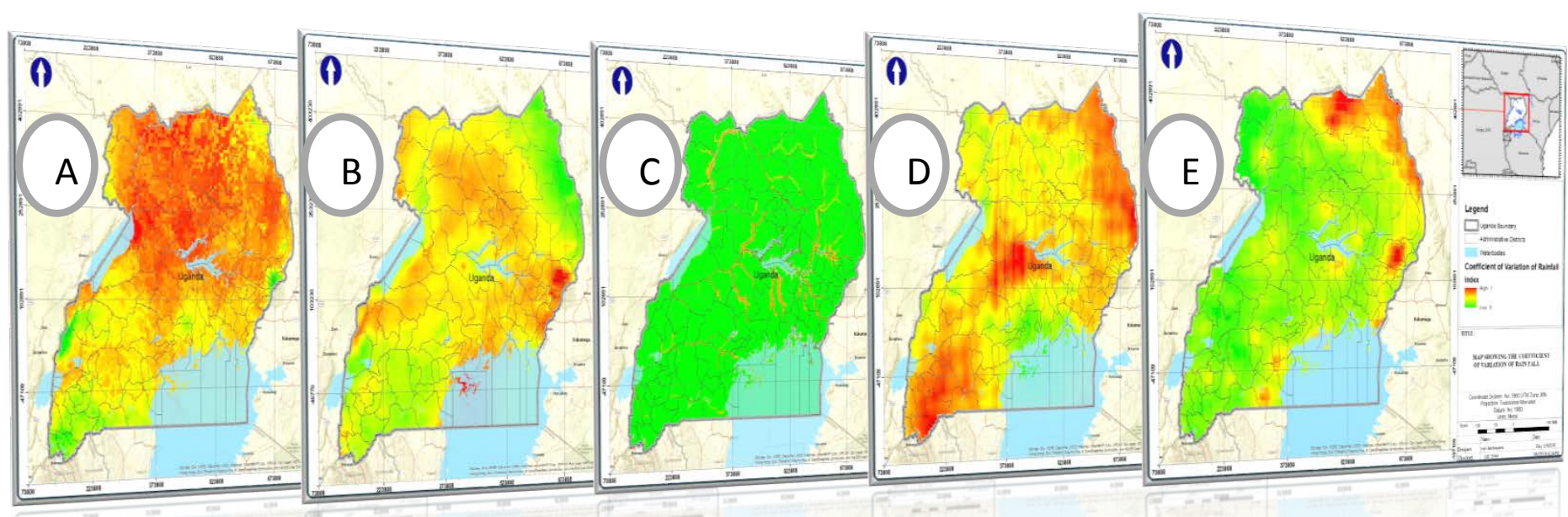

Figure: 3 Mapped extreme weather and climate events indicators

\subsection{Weighting}

This was accomplished using Principle Component Analysis (PCA) as statistical weighting technique due to its ability to group together individual components which are collinear. PCA was carried out and Eigen values and vectors for the input indicators obtained as an ingredient for 
obtaining factor loadings in factor analysis. Table 3 shows the results from PCA based on factor analysis rotation matrix obtained using the varimax rotation method.

The rotation covered eleven iterations. The rotation involved re-distributing the values' commonalities so that a clearer pattern of loadings emerges. The idea was to find an arrangement in which test values load high on one factor and low on others. In this study, four factors with Eigen values greater than one are observed for extraction, the percentage of variance represents how much of the total variability is accounted for by each of the factors. And also, the rotated sums of the squared loadings accounts for the factors that met the cut- off criterion.

Table: 1 Normalized indicator weight

\begin{tabular}{|c|c|c|c|c|c|c|c|}
\hline \multirow[b]{2}{*}{ Component } & \multicolumn{3}{|c|}{ Initial Eigenvalues } & \multicolumn{3}{|c|}{ Rotation Sums of Squared Loadings } & \multirow{2}{*}{$\begin{array}{l}\text { Normalized } \\
\text { Weight }\end{array}$} \\
\hline & Total & $\%$ of Variance & Cumulative \% & Total & $\%$ of Variance & Cumulative \% & \\
\hline 1 & 1.810 & 36.200 & 36.200 & 1.611 & 32.220 & 32.220 & 1.000 \\
\hline 2 & 1.032 & 20.648 & 56.848 & 1.132 & 22.645 & 54.865 & 0.424 \\
\hline 3 & 1.010 & 20.198 & 77.046 & 1.109 & 22.186 & 77.051 & 0.408 \\
\hline 4 & .689 & 13.773 & 90.820 & & & & 0.170 \\
\hline 5 & .459 & 9.180 & 100.000 & & & & 0.000 \\
\hline
\end{tabular}

Results show that factor 1 accounts for 32.220\% of the variability in all 5 variables. Factor 2 accounts for $22.645 \%$, factor 3 accounts for $22.186 \%$. Thus the first three factors account for $77.051 \%$ of the total variance.

The loadings through a rotated component matrix obtained show that the first principal component were heavily loaded on rain and drought, the second component loaded on temperature and coefficient of variation of rainfall and the third component loaded on the flood as shown in Table 4

Table 4 The rotated component matrix indicating the actor loadings for each indicator

\begin{tabular}{|l|c|c|c|}
\hline Rotated Component Matrix & Component \\
\cline { 2 - 4 } & 1 & 2 & 3 \\
\hline Temperature & .465 & .470 & -.420 \\
\hline Flood & .019 & -.050 & .961 \\
\hline Rain & .996 & .068 & .022 \\
\hline Drought & .928 & -.053 & -.062 \\
\hline Coefficient of variation of rainfall & -.021 & .949 & -.069 \\
\hline Indicator Weight & 1.000 & 0.424 & 0.408 \\
\hline
\end{tabular}




\subsection{Multi Criteria Decision Analysis (MCDA)}

With the weights for the sub indicators determined through principal component analysis, the weighted linear combination (WLC) was adopted to aggregate the spatial variables for the subsequent calculation of the CCCI. This approach multiplies normalized criteria scores by relative criteria weights for each sub indicator (Geldermann \& Rentz 2007: Nyerges \& Jankowski 2010). Drobne et al., (2009) further guides that the total score is obtained by multiplying the importance weight (w) assigned to each sub indicator $(\mathrm{x})$ by the scaled value given for that into the alternative and then summing the products over all sub indicators(S) as indicated in Formula $S=\mathrm{w}_{\mathrm{i}} \mathrm{x}_{\mathrm{i}} \ldots \ldots \ldots .2$

$$
S=\sum w_{i} x_{i} \ldots \ldots \ldots \ldots \ldots \ldots \ldots . \ldots \ldots
$$

The Formula $S=\mathrm{w}_{\mathrm{i}} \mathrm{x}_{\mathrm{i}} \ldots \ldots \ldots \ldots \ldots \ldots \ldots . \ldots 2$ : achieves the data integration of the CCCI hotspot in an object based image analysis (OBIA) environment. However there was need for concepts adding value to these strands of data by extracting meaningful information (Lang et al, 2010). To address this challenge, Kienbeeger et al. (2008), proposes the adopted geon concept; a generic concept to reduce complexity on successive levels of intervention. For each unit, an index of cumulative climate change (CCCI) was calculated. Any given delineated object with cumulative sub indicators $\left(s_{1} \ldots \ldots s_{5}\right)$ had the CCCI calculated and the magnitude of the resulting vector output in a multidimensional space as;-

$$
|C C C I|=\sqrt{s_{1}+s_{2}+s_{3}+s_{4}+s_{5}} \ldots \ldots \ldots \ldots \ldots \ldots \ldots . \ldots
$$

The final vector value depicts the distance and position of each unit within the feature space. This reflects the notion of the regionalization. The result vector was mapped as shown in Figure 4 to represent decomposable extreme weather and climate events hotspots for Uganda

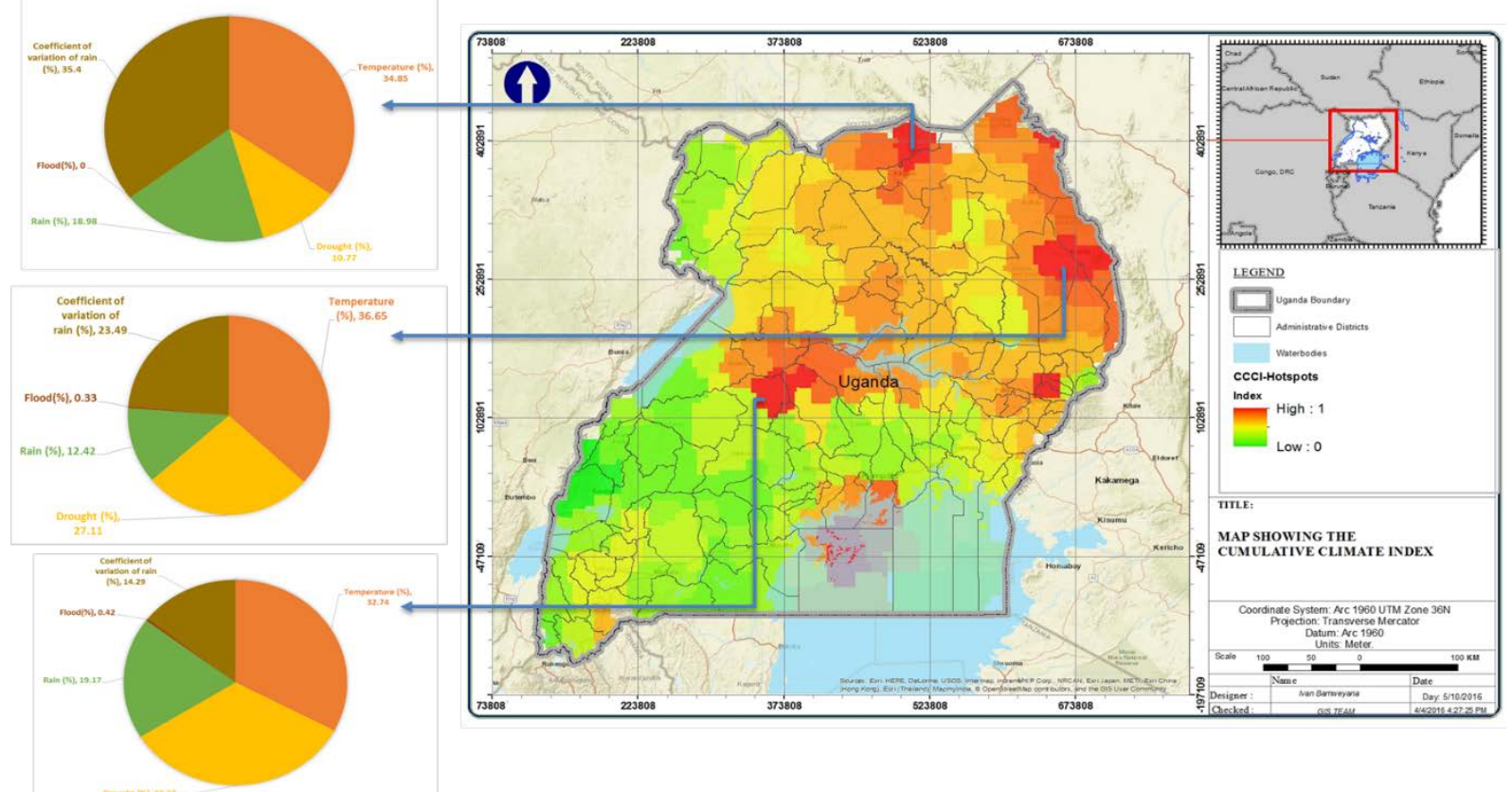

Figure: 4 Unit based cumulative national extreme weather and climate hotspots 


\subsection{Sensitivity Analysis}

Whereas these Spatial composite indicators are increasingly being used for bench-making countries performances (Saisana \& Tarantola 2002), there are doubts often raised about the robustness of the resulting index rankings and about the significance to the associated policy message (Saisana et al, 2004). In this case, sensitivity analysis was undertaken to assess the robustness of the composite indicator in terms of; mechanism for including or excluding an indicator, the normalization scheme, the imputation of missing data, the choice of weights and the aggregation method (OECD, 2011).

Variance based methods of sensitivity analysis have assessed themselves as versatile and effective among the various available techniques for sensitivity analysis of model output (Annoni et al., 2010). Unlike experimental weighting, where the effects of factors are over estimated, variance based methods look at the entire factors distribution, using customarily Monte Carlo methods of various sophistication (Archer et al., 1997). Annoni et al., (2010) further asserts that the number of terms in the analysis of variances (ANOVA) decomposition of the variance of a model $k$ grows as $2^{k}$. This makes it customary to compute just two sets of index; the $k$ 'first order' and $k$ 'total' effects (Saltelli et al., 1999). According to Annoni et al., (2010), for a given model of the form $y=f\left(x_{1}, x_{2}, \ldots . x_{k}\right)$, with $y$ a scalar, a variance based first order effect for a generic factor $x_{i}$ can be written as;-

$$
v_{x_{i}}\left(E_{x \sim i}\left(y \mid x_{i}\right)\right) \ldots \ldots \ldots \ldots \ldots \ldots \ldots \ldots . \ldots . \ldots . \ldots
$$

Where $x_{i}$ is the $i$-th factor and $x_{\sim i}$ denotes the matrix of all factors but $x_{i}$. The meaning of the inner expectation operator is that the mean of $y$ is taken over all possible values of $x_{\sim i}$ while keeping $x_{i}$. The associated sensitivity measure (first order sensitivity co-efficient) written as:

$$
S_{i}=\frac{v_{x_{i}}\left(E_{x \sim i}\left(y \mid x_{i}\right)\right)}{v(y)} \ldots \ldots \ldots \ldots \ldots \ldots \ldots . \ldots \ldots . . \ldots \ldots
$$

Where $v(y)=v_{x_{i}}\left(E_{x \sim i}\left(y \mid x_{i}\right)+E_{x_{i}}\left(v_{x \sim i}\left(y \mid x_{i}\right)\right) \ldots \ldots \ldots \ldots \ldots \ldots \ldots . \ldots \ldots .2\right.$

$s_{i}$ is a normalized index, as $v_{x_{i}}\left(E_{x \sim i}\left(y \mid x_{i}\right)\right)$ varies between zero and $v(y) . v_{x_{i}}\left(E_{x \sim i}\left(y \mid x_{i}\right)\right)$ measures the first order (e.g. additive) effect of $x_{i}$ on the model output, while $E_{x_{i}}\left(v_{x \sim i}\left(y \mid x_{i}\right)\right)$ is customarily called the residual.

The total effect order variance based measure is the total effect in index:

$$
s_{T i}=\frac{E_{x \sim i}\left(v_{x i}\left(y \mid x_{\sim i}\right)\right)}{v(y)}=1-\frac{v_{x \sim i}\left(E_{x_{i}}\left(y \mid x_{\sim i}\right)\right)}{v(y)} \ldots \ldots \ldots \ldots \ldots \ldots \ldots . . \ldots \ldots
$$

$s_{T i}$ Measures the total effect, i.e. first and higher order effects (interactions) of factor $x_{i}$. One way to visualize this is by considering that $v_{x \sim i}\left(E_{x_{i}}\left(y \mid x_{\sim i}\right)\right)$ is the first order effect of $x_{\sim i}$, so that $v(y)$ minus $v_{x \sim i}\left(E_{x_{i}}\left(y \mid x_{\sim i}\right)\right)$ give the contribution in of all terms in the variance decomposition which include $x_{i}$. This qualitatively determines the indicators that have the most influence on site ranking .This accounts for the rank robustness of the climate change hotspot model.

The indicators were each subjected to a minimum weight string of 0.01 and a maximum weight string of 0.9 and run through ten thousand $(10,000)$ Monte Carlo simulations. Consequently the global sensitivity analysis average shift in ranks indices S 'first order' and ST 'total effect' were extracted 
as shown in Table 5. Table.5 presents the GSA results in percentile format. The first order sensitivity index (s) represents for indicators that, if fixed independently, would reduce the variance shift in ranks most. This accounts for influence of indicators. The total effect index (ST) represents the significance of the indicators to the composite.

Table 5; Global sensitivity analysis percentile influence and significance

\begin{tabular}{|c|c|c|}
\hline Factor & $\mathbf{\% S}$ & $\mathbf{\% S T}$ \\
\hline Drought & 40.7 & 44.5 \\
\hline Temperature & 14.7 & 11.9 \\
\hline Mean_Rain & 13.3 & 16.3 \\
\hline Mean_Flood & 9 & 8.1 \\
\hline Mean_Cov_Rain & 13.6 & 19.2 \\
\hline NONL & 9.7 &
\end{tabular}

\section{Results and Discussion}

\subsection{Static extreme weather and climate events hotspot Identification}

The result hotspot map was mapped as shown in Figure 4 to represent decomposable extreme weather and climate events hotspots for Uganda .Areas that are highly susceptible to extreme climate and weather events are indicated on the continuum of red to green. Red represents the most susceptible (hot spots) and thins down to green which represents the less susceptible (cold spots). In general, Figure 4 shows high CCCI hotspot values in the administrative regions of Eastern Uganda, south western Uganda, parts of western central and the far north. Furthermore, homogenous units of weather and climate extremes were explored and their sub-indicators decomposed into their percentile contribution to respective units as shown by the pie charts in Figure4

\subsection{Web Visualisation Tool}

With the emersion of this spatially based extreme weather and climate hotspots static map, open access to the same becomes essential. This visualization tool has been designed to allow for the decomposition of the identified hotspots into their underlying sub-indicators and for open access as well as interrogation of extreme weather and climate hotspots data in Uganda as shown in Figure 5. The tool was developed using ArcGIS online. It is furnished with abilities to, print visualized output, view individual layer indices independently, analyse and extract the attribute table, ability to change base maps, measure distances and areas, scale, search places and pick the coordinates. 


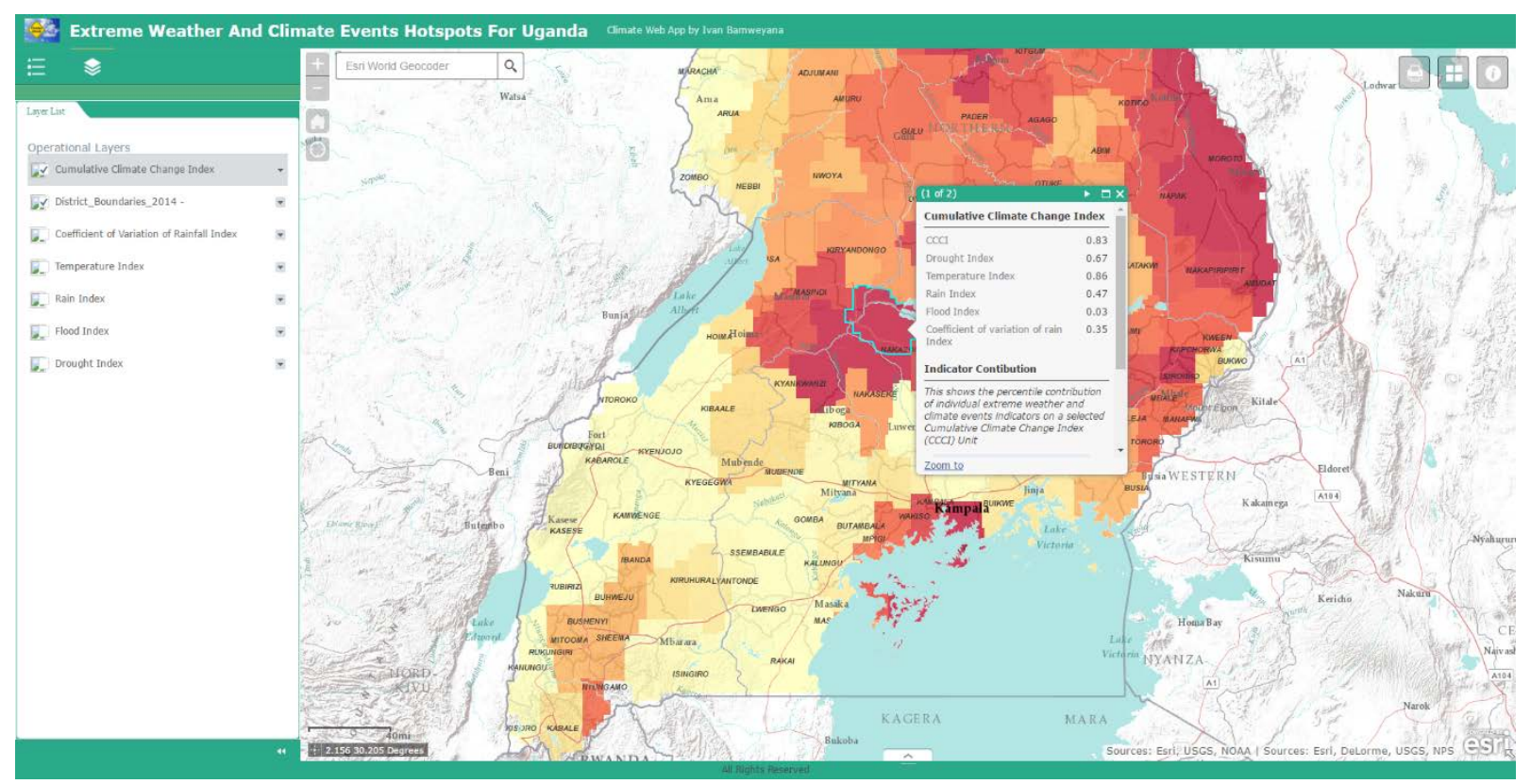

Figure: 5 ArcGIS online based visualization extreme weather and climate events hotspot tool

\section{Conclusions and Recommendations}

This study set out to model decomposable climate change hot spots representing the extreme weather and climate events aggregated in a Cumulative Climate Change Index (CCCI). This was to allow one decompose a given hotspot unit into contributing sub indicators. Conclusively, the modelled national extreme weather and climate events hotspot bring forward a holistic view of decomposable spatially based indicators. The research also provides an additional understanding of the complex interplay of the contributing underlying weather climatic events and their spread in terms of influence and intensity in various regions.

The research recommends to policy makers, to not only decompose the identified hotspots into the underlying sub indicators but also prioritize intervention areas. Additionally, this provides additional information to yield informed policies for effective climate change adaptation procedures to be used in mitigating the impacts among vulnerable communities in the country. To researchers, initiation of this work provides room for time series assessments, this will enable stakeholders monitor spatial shrinkage and expansion of related hotspots. Researchers will so be able to avail projections of future hotspot behaviour under this arrangement.

\section{References}

ACCRA, (2010). A review of Uganda's Disaster Risk Reduction and Climate Change Adaptation Status. Africa Climate Change Resilience Alliance (ACCRA). M. Barihaihi, Kampala

Drobne, S., \& Lisec, A. (2009). Multi-attribute decision analysis in GIS: weighted linear combination and ordered weighted averaging. Informatica, 33(4).

Freudenberg M. (2003), Composite indicators of country performance: a critical assessment, OECD, Paris. 
Geldermann, J. and Rentz, O. (2007). Multi-criteria decision support for integrated technique assessment. In: Kropp, J. and Scheffran, J. (eds) Advanced methods for decision making and risk management in sustainability science. New York: Nova Science Publishers, pp. 257-273.

Hagenlocher, M., Lang, S., Holbling, D., Tiede, D., \& Kienberger, S. (2014). Modeling hotspots of climate change in the Sahel using object-based regionalization of multidimensional gridded datasets. Selected Topics in Applied Earth Observations and Remote Sensing, IEEE Journal of, 7(1), 229-234.

Hepworth, N D. (2010). Climate change vulnerability and adaptation preparedness in Uganda. Heinrich Böll Foundation, Nairobi, Kenya.

IPCC SREX, (2012): Summary for Policymakers. In: Managing the Risks of Extreme Events and Disasters to Advance Climate Change Adaptation [Field, C.B., V. Barros, T.F. Stocker, D. Qin, D.J. Dokken, K.L. Ebi, M.D. Mastrandrea, K.J. Mach, G.-K. Plattner, S.K. Allen, M. Tignor, and P.M. Midgley (eds.)]. A Special Report of Working Groups I and II of the Intergovernmental Panel on Climate Change.

Cambridge University Press, Cambridge, UK, and New York, NY, USA, pp. 1-19.

Jacobs R., Smith P. and Goddard M. (2004), measuring performance: an examination of composite performance indicators, Centre for Health Economics, Technical Paper Series 29.

Kienberger and Hagenlocher (2014) Spatial-explicit modelling of social vulnerability to malaria in East Africa International Journal of Health Geographic’s, 13:29 http://www.ijhealthgeographics.com/content/13/1/29

Lang, S., F. Albrecht, S. Kienberger \& D. Tiede, (2010). Object validity for operational tasks in a policy context. Journal for Spatial Science, 55 (1), 9-22.

Lavell, A., M. Oppenheimer, C. Diop, J. Hess, R. Lempert, J. Li, R. Muir-Wood, and S. Myeong, (2012): Climate change: new dimensions in disaster risk, exposure, vulnerability, and resilience. In: Managing the Risks of Extreme Events and Disasters to Advance Climate Change Adaptation [Field, C.B., V. Barros, T.F. Stocker, D. Qin, D.J. Dokken, K.L. Ebi, M.D. Mastrandrea, K.J. Mach, G.-K. Plattner, S.K. Allen, M. Tignor, and P.M. Midgley (eds.)]. A Special Report of Working Groups I and II of the Intergovernmental Panel on Climate Change (IPCC). Cambridge University Press, Cambridge, UK, and New York, NY, USA, pp. 25-64.

Mazziotta M., Pareto A. (2012). A Non-compensatory Approach for the Measurement of the Quality of Life. In: Maggino F. \& Nuvolati G. (eds). Quality of Life in Italy: Research and Reflections. New York: Springer.

Nyerges, T. L. and Jankowski, P. (2010). Regional and urban GIS: a decision support approach.

OECD. (2011). Handbook on constructing composite indicators, methodology and user guide, European commission.

Oxfam. (2008), Turning Up the Heat: Climate Change and Poverty in Uganda, July 2008, Oxfam GB

Saisana M. and Tarantola S. (2002), State-of-the-art report on current methodologies and practices for composite indicator development, EUR 20408 EN, European Commission-JRC: Italy.

Saltelli, A., S. Tarantola, and K. Chan, (1999), “A quantitative, model independent method for global sensitivity analysis of model output”, Technometrics, 41(1): 39-56.

Salzman, Julia and Andrew Sharpe (2003), Methodological Choices Encountered in the Construction of Composite Indices of Economic and Social Well-Being, Paper presented to the Canadian Economics Association conference, 31 May 2003. Available: http://www.csls.ca/events/cea2003/salzman-typolcea2003.pdf 